\title{
Increased expression of BPI fold-containing family A member 1 is associated with metastasis and poor prognosis in human colorectal carcinoma
}

\author{
HUANAN WANG ${ }^{1,2^{*}}$, DONGMEI JIANG ${ }^{1,2^{*}}$, WENLU LI $^{1,2}$ and SHUANG WANG ${ }^{1,2}$ \\ ${ }^{1}$ Department of Pathology, Nanfang Hospital; ${ }^{2}$ Department of Pathology, School of Basic Medical Sciences, \\ Southern Medical University, Guangzhou, Guangdong 510515, P.R. China
}

Received December 3, 2015; Accepted May 26, 2017

DOI: $10.3892 / \mathrm{ol} .2017 .6662$

\begin{abstract}
Bactericidal or permeability-increasing protein fold-containing family A member 1 (BPIFA1) has been demonstrated to be involved in inflammatory responses in the upper airway and the progression of non-small cell lung cancer. However, the expression levels of BPIFA1 and its clinical prognostic significance in colorectal carcinoma (CRC) has not yet been elucidated. Reverse transcription-polymerase chain reaction and immunohistochemistry were used to analyze the expression levels of BPIFA1 in CRC and normal mucosal tissues. The associations between BPIFA1 expression levels and clinicopathological characteristics, and its predictive value for prognosis in CRC, were statistically evaluated as appropriate. The expression levels of BPIFA1 were revealed to be upregulated at the transcriptional and translational levels in CRC tissues, compared with in normal mucosal tissues. A high expression level of BPIFA1 is significantly associated with invasion depth $(\mathrm{P}=0.040)$, lymph node metastasis $(\mathrm{P}=0.035)$ and distant metastasis $(\mathrm{P}=0.010)$. Furthermore, Kaplan-Meier analysis indicated that BIPFA1 overexpression is associated with short survival time, and the Cox proportional hazards model of risk analysis indicated that BPIFA1 is an independent prognostic factor for patients with CRC. The results of the present study suggested that BPIFA1 expression is upregulated in CRC tissues, and that an increased expression level of BPIFA1 is associated with
\end{abstract}

Correspondence to: Professor Shuang Wang, Department of Pathology, School of Basic Medical Sciences, Southern Medical University, 1023 Shatainan Road, Guangzhou, Guangdong 510515, P.R. China

E-mail: shuangw@126.com

${ }^{*}$ Contributed equally

Abbreviations: BPIFA1, BPI fold-containing family A member 1; CRC, colorectal carcinoma; NSCLC, non-small cell lung cancer; PLUNC, palate, lung and nasal epithelium clone protein; SPLUNC1, short palate, lung and nasal epithelium clone protein 1; qPCR, quantitative polymerase chain reaction

Key words: BPI fold-containing family A member 1, colorectal carcinoma, prognosis, metastasis, invasion tumor invasion, metastasis and poor prognosis, indicating that BPIFA1 may be a potential clinical prognostic predictor and therapeutic target for patients with CRC.

\section{Introduction}

Colorectal carcinoma (CRC) is the one of the most common types of cancer, and is the fifth leading cause of cancer-associated mortalities worldwide (1). Despite recent advancements in the surgical techniques, radiotherapy and chemotherapy available to patients diagnosed with CRC over the past several decades, the overall survival rate has not significantly improved. The existence of numerous known carcinogens and varying genetic backgrounds makes it difficult to determine which factors are most important in the development of CRC. Thus, there is a requirement to further understand the underlying molecular mechanisms and identify novel prognostic biomarkers and therapeutic targets to provide improved treatment strategies for CRC.

Bactericidal or permeability-increasing protein fold-containing family A member 1 (BPIFA1) is a protein-coding gene specifically expressed in the upper airways and nasopharyngeal regions. A number of previous studies have demonstrated that BPIFA1 is involved in various physiological and pathological processes (2-19). It is considered to be involved in inflammatory responses to irritants in the upper airway (2-7). BPIFA1 may decrease mycoplasma pneumonia expression levels and inhibit interleukin 8 (8). BPIFA1 protein was also revealed to have antibacterial activity against gram-negative bacteria $(9,10)$. The anti-inflammatory function has been associated with the regulation of macrophagic activity (10), particularly cellular responses to lipopolysaccharide (11). Previous studies have demonstrated that the expression levels of BPIFA1 are upregulated in lung cancer (12-14), gastric cancer (15) and head and neck neoplasms, such as mucoepidermoid carcinoma and nasopharyngeal carcinoma (16-19). BPIFA1 (LUNX) was identified to be a potential marker for the micro-metastasis of non-small cell lung cancer (NSCLC) (14). BPIFA1 was also revealed to be a novel marker able to distinguish gastric hepatoid adenocarcinoma from primary hepatocellular carcinoma (15). Recently, it was demonstrated that anti-LUNX antibody slowed tumor growth and metastasis and improved the survival time of mice bearing lung 
cancer xenografts (20). However, little is known about BPIFA1 in CRC.

In the present study, the mRNA and protein expression levels of BPIFA1 in clinically resected human CRC and adjacent noncancerous tissues were examined by quantitative polymerase chain reaction (qPCR) and immunohistochemistry (IHC), and the association between BPIFA1 protein expression levels and the prognosis of patients with CRC was analyzed.

\section{Materials and methods}

Tissue specimens. Fresh formalin-fixed and paraffin-embedded CRC tumor tissue samples were obtained from patients with a diagnosis of primary CRC, who underwent surgical resection at Nanfang Hospital, Southern Medical University (Guangzhou, China) from February 2000 to November 2010. The use of tissues for this study was approved by the Ethics Committee of Nanfang Hospital, Southern Medical University. Written informed consent was obtained from all patients prior to enrollment in the present study. A total of 36 cases of fresh CRC tissue (20 males and 16 females) of a mean age of 52.08 \pm 9.16 (range 35-67) were snap-frozen in liquid nitrogen and stored at $-80^{\circ} \mathrm{C}$ until further use. A total of 118 cases of archived CRC tissue samples and 73 adjacent non-tumors tissues were from Nanfang Hospital were used for immunohistochemistry to investigate the expression of BPIFA1 protein. None of the patients received pre-operative chemotherapy or radiotherapy. The patients included 76 males and 42 females, ranging in age from $24-88$ years (mean, $57.83 \pm 1.35$ years). During the follow-up period, 56 patients succumbed to disease between months 1 and 122 months of (median, 56 months).

$R N A$ isolation and reverse transcription-quantitative polymerase chain reaction ( $R T-q P C R)$. Total RNA was extracted from 50-100 mg of tissue using TRIzol Reagent (Takara Biotechnology Co., Ltd., Dalian, China). cDNA was synthesized using the PrimeScript RT reagent kit (Takara Biotechnology Co., Ltd.). RT-qPCR was performed to detect the expression of BPIFA1 using the One-Step SYBR PrimeScript RT-PCR kit (Takara Biotechnology Co., Ltd.), using the following thermal cycling profile: $95^{\circ} \mathrm{C}$ for $5 \mathrm{~min}$, followed by 40 cycles of amplification $\left(95^{\circ} \mathrm{C}\right.$ for $40 \mathrm{sec}, 56^{\circ} \mathrm{C}$ for $40 \mathrm{sec}$ and $72^{\circ} \mathrm{C}$ for $\left.40 \mathrm{sec}\right)$, followed by dissociation curve analysis to validate the amplification of the product, normalized to the expression of $\beta$-actin. The primers were as follows: $\beta$-actin forward, 5 -TAAGGAGAA GCTGTGCTACG-3'; reverse, 5'-GACTCGTCATACTCCTGC TT-3'; BPIFA1 forward, 5'-GTGGGGGAGAGAGAG-GAG AC-3', reverse, 5'-GTCAAGCTTCCTGCAAGACC-3'. The assay was performed in triplicate for each case to allow for the assessment of technical variability.

IHC. IHC staining of tissue samples was performed according to a previously described protocol (21) using a Dako EnVision System (Dako; Agilent Technologies, Inc., Santa Clara, CA, USA), in order to evaluate BPIFA1 protein expression levels in 118 human CRC tissue samples. Briefly, the sections were incubated with primary antibodies against BPIFA1 (cat. no. LS-B3549; dilution 1:400, LifeSpan BioSciences, Inc., Seattle, WA, USA) for $1 \mathrm{~h}$ at room temperature. Following incubation with the peroxidase-conjugated secondary

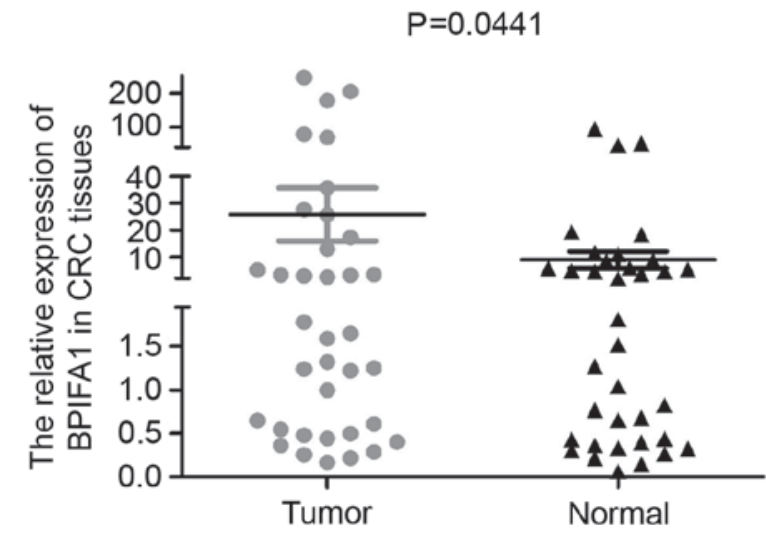

Figure 1. The expression levels of BPIFA1 mRNA in paired CRC and adjacent normal tissues investigated by quantitative polymerase chain reaction. BPIFA1, BPI fold-containing family A member 1; CRC, colorectal cancer.

antibody from the Dako EnVision System (ready-to-use dilution), expression patterns were visualized using the substrate diaminobenzidine to generate a stained product. For negative controls, the antibodies were replaced with normal goat serum (Maixin Biotech, Fuzhou, China) and incubated under the same conditions as the BPIFA1 antibody.

Evaluation of staining for BPIFA1. To eliminate inter-observer bias, the expression levels of BPIFA1 were reviewed and scored by two independent pathologists who were blinded to the patients' clinicopathological data. Staining for BPIFA1 was assessed using a method previously described $(22,23)$. On a scale of 0-3, the staining intensity was scored as follows: Negative (no staining, 0), weak (light yellow, 1), medium (yellow-brown, 2) or strong (brown, 3). The extent of the staining was defined as the percentage of positively stained areas of tumor cells or normal mucosal epithelial cells relative to the whole tumor area or to the entire section for the normal tissue samples. The extent of staining was scored on a scale of $0-4$ as follows: $0,0 \% ; 1,>0-\leq 25 \% ; 2,>25-\leq 50 \% ; 3,>50-\leq 75 \%$ and $4,>75-<100 \%$. The sum of the staining-intensity and staining-extent scores was used as the final staining score for BPIFA1. For statistical analysis, a final staining score of $\geq 3$ was regarded to represent high expression levels.

Statistical analysis. The SPSS software package (version 16.0; SPSS Inc., Chicago, IL, USA) was used for all statistical analysis. Differences in BPIFA1 expression levels in fresh tissue samples were evaluated using the paired Student's t-test. Differences between variables were determined using the $\chi^{2}$ test. Survival curves for the patients with various expression levels of BPIFA1 protein were constructed using the Kaplan-Meier method and compared using the log-rank test. Cox proportional hazards regression analysis was performed for univariate and multivariate analyses of the prognostic values. $\mathrm{P}<0.05$ was considered to indicate a statistically significant difference.

\section{Results}

Expression of BPIFA1 mRNA expression level in CRC tissues and adjacent noncancerous tissues. The expression levels of BPIFA1 mRNA in 36 paired human CRC tissues and 
A

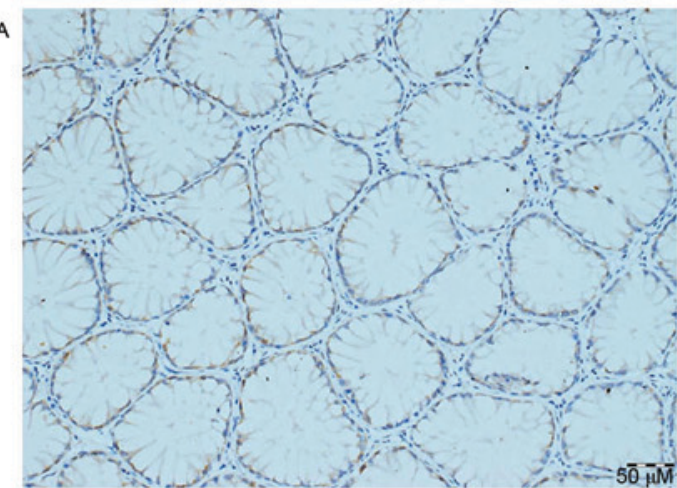

$c$

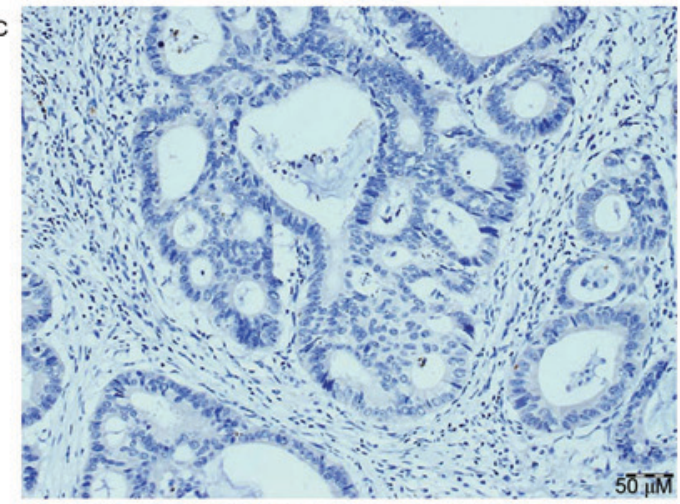

E

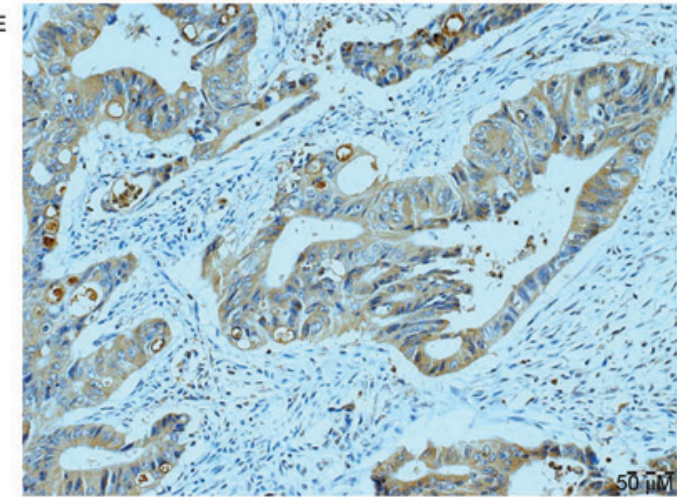

G .

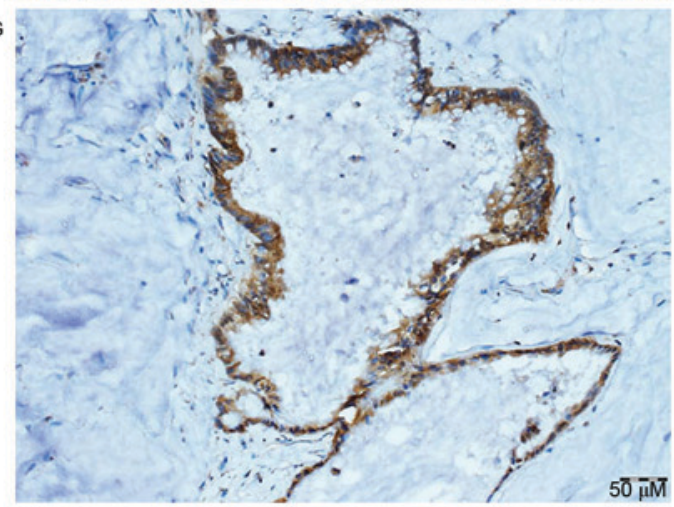

$\mathrm{B}$

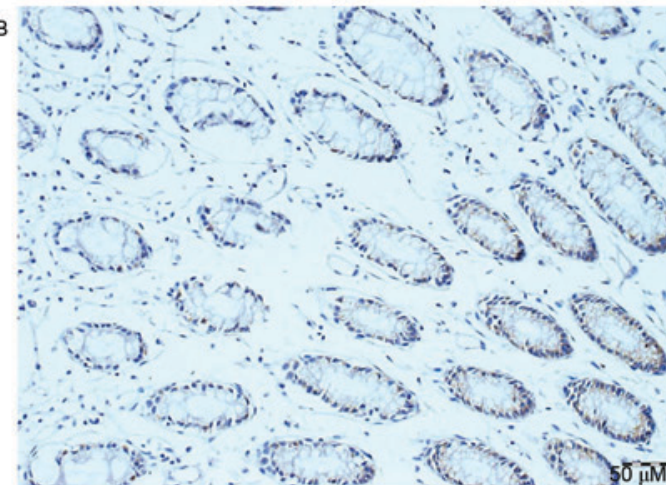

D
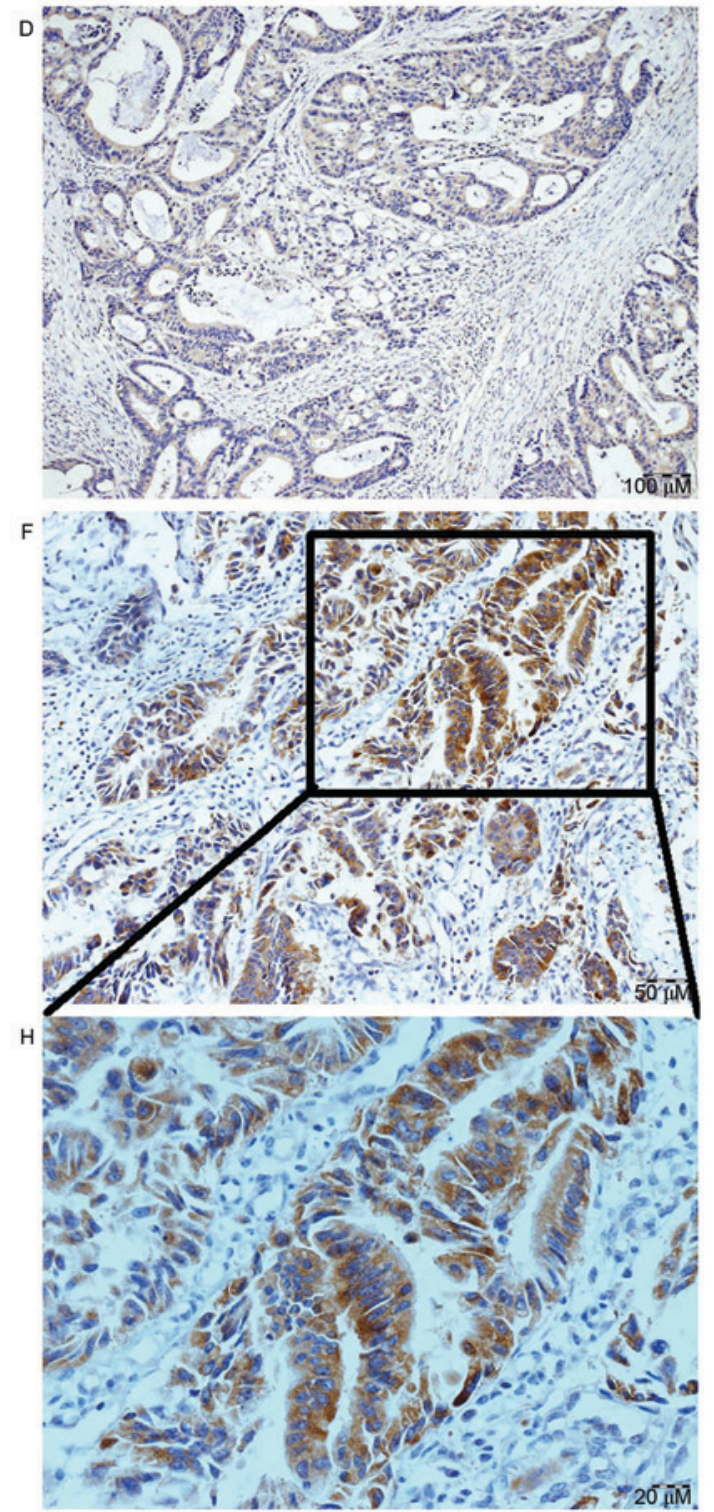

Figure 2. Expression level analysis of BPIFA1 protein in normal colorectal mucosa and CRC tissues by immunohistochemistry. (A and B) Negative or weak expression levels of BPIFA1 in normal colorectal mucosa (original magnification, x200); (C-H) BPIFA1 expression levels in human CRC tissue samples. (C) Negative expression level of BPIFA1 (original magnification, x200); (D) weak expression level of BPIFA1 (original magnification, x100); (E) medium expression level of BPIFA1 (original magnification, x200); (F-H) high expression level of BPIFA1 in CRC tissue samples (original magnification, $\mathrm{x} 200$, x200 and $\mathrm{x} 400$, respectively). BPIFA1, BPI fold-containing family A member 1; CRC, colorectal cancer.

adjacent noncancerous tissues were quantified by qPCR. The results of the present study indicated that there was variability in the expression levels of BPIFA1 across the tissue samples. Notably, BPIFA1 mRNA was upregulated in CRC tissues, when compared with in adjacent noncancerous tissues (Fig. 1; $\mathrm{P}=0.0441$ ), and the majority of CRC tissues exhibited a $>2$-fold increase in BPIFA1 expression levels, as compared with normal tissues. 
Table I. Associations between the clinicopathological features and expression levels of BPIFA1.

\begin{tabular}{|c|c|c|c|c|c|}
\hline \multirow[b]{2}{*}{ Characteristics } & \multirow[b]{2}{*}{$\mathrm{n}$} & \multicolumn{2}{|c|}{ BPIFA1 expression } & \multirow[b]{2}{*}{ P-value } & \multirow[b]{2}{*}{$\chi^{2}$} \\
\hline & & Low $(\%)$ & $\operatorname{High}(\%)$ & & \\
\hline \multicolumn{6}{|l|}{ Sex } \\
\hline Male & 76 & $32(42.11)$ & $44(57.89)$ & & \\
\hline Female & 42 & $16(38.10)$ & $26(61.90)$ & 0.671 & 0.180 \\
\hline \multicolumn{6}{|l|}{ Age (years) } \\
\hline$\leq 57$ & 59 & $21(35.59)$ & $38(64.41)$ & & \\
\hline$>57$ & 59 & $27(45.76)$ & $32(54.24)$ & 0.261 & 1.264 \\
\hline \multicolumn{6}{|l|}{ Tumor site } \\
\hline Proximal colon & 37 & $15(41.57)$ & $22(58.43)$ & & \\
\hline Distant colon & 26 & $13(50.00)$ & $13(50.00)$ & & \\
\hline Rectum & 55 & $20(36.36)$ & $35(63.64)$ & 0.506 & 1.361 \\
\hline \multicolumn{6}{|c|}{ Tumor size (diameter in $\mathrm{cm}$ ) } \\
\hline$<5$ & 60 & $25(41.67)$ & $35(58.33)$ & & \\
\hline$\geq 5$ & 58 & $23(39.65)$ & $35(60.35)$ & 0.879 & 0.023 \\
\hline \multicolumn{6}{|c|}{ Tumor differentiation } \\
\hline Good & 51 & $26(50.98)$ & $25(49.02)$ & & \\
\hline Moderate & 45 & $16(35.56)$ & $29(64.44)$ & & \\
\hline Poor & 22 & $6(27.27)$ & $16(72.73)$ & 0.112 & 4.371 \\
\hline \multicolumn{6}{|l|}{ T-stage } \\
\hline $1-2$ & 31 & $18(58.06)$ & $13(51.94)$ & & \\
\hline 3 & 73 & $27(36.99)$ & $46(63.01)$ & & \\
\hline 4 & 14 & $3(21.43)$ & $11(78.57)$ & $0.040^{\mathrm{a}}$ & 6.445 \\
\hline \multicolumn{6}{|l|}{$\mathrm{N}$-stage } \\
\hline $1-2$ & 48 & $14(29.17)$ & $34(70.83)$ & & \\
\hline 0 & 70 & $34(48.57)$ & $36(51.43)$ & $0.035^{\mathrm{a}}$ & 4.443 \\
\hline \multicolumn{6}{|l|}{ Distant metastasis } \\
\hline 1 & 13 & $1(7.69)$ & $12(92.31)$ & & \\
\hline 0 & 105 & $47(44.34)$ & $58(55.66)$ & $0.010^{\mathrm{a}}$ & 6.587 \\
\hline
\end{tabular}

${ }^{a} \mathrm{P}<0.05$. BPIFA1, BPI fold containing family A member 1 ; $\mathrm{n}$, number; $\mathrm{T}$, tumor; $\mathrm{N}$, node.

Expression levels of BPIFAl protein in CRC tissues. The present study evaluated the protein expression levels of BPIFA1 in archived paraffin-embedded primary CRC tissues and normal colon tissue samples by performing immunohistochemical staining. The results revealed that BPIFA1 protein was expressed in the cytoplasm of benign and malignant epithelial cells. It was observed that BPIFA1 protein was expressed in 23/73 (31.51\%) normal colon mucosa samples. In comparison, BPIFA1 was expressed in 110/118 (93.22\%) CRC tumor tissue samples. The expression level of BPIFA1 was markedly upregulated in CRC tissues compared with in normal mucosa tissues $(\mathrm{P}<0.001)$. According to the aforementioned reclassification guidelines, the present study determined there was high BPIFA1 expression in 70/118 (59.32\%) of the CRC tissue samples (Fig. 2).

Association between clinicopathological characteristics and BPIFAl expression level in patients with CRC. The association analysis between clinicopathological characteristics and BPIFA1 protein expression level was evaluated in individuals.
The data is presented in Table I. The upregulation of BPIFA1 was significantly associated with invasion depth $(\mathrm{P}=0.040)$, positive regional lymph node metastasis $(\mathrm{P}=0.035)$ and distant metastasis $(\mathrm{P}=0.010)$; conversely, there was no association with age, sex, tumor site, tumor size and differentiation grade $(\mathrm{P}>0.05)$.

Association between BPIFAl expression level and patient survival. The present study used Kaplan-Meier analysis as a first step to assess the prognostic value of BIPFA1 in CRC. It was observed that the expression level of BPIFA1 was significantly associated with overall survival (log-rank test statistic=11.898; $\mathrm{P}=0.001 ;$ Fig. 3). The high expression level of BPIFA1 was associated with a shorter survival time for patients with CRC (high BPIFA1 expression group, $62.63 \pm 6.08$ months; low BPIFA1 expression group, $95.57 \pm 6.12$ months).

Univariate and multivariate analyses of prognostic variables in patients with $C R C$. In order to evaluate the expression levels of BPIFA1 as an independent prognostic factor for 
Table II. Summary of overall survival analyses by univariate and multivariate Cox regression analysis.

\begin{tabular}{|c|c|c|c|c|c|c|}
\hline \multirow[b]{2}{*}{ Variables } & \multicolumn{3}{|c|}{ Univariate analysis } & \multicolumn{3}{|c|}{ Multivariate analysis } \\
\hline & P-value & HR & $95 \% \mathrm{CI}$ & P-value & HR & $95 \% \mathrm{CI}$ \\
\hline Sex & 0.4410 & 0.8010 & $0.456-1.408$ & & & \\
\hline Age & 0.4770 & 1.2540 & $0.672-2.340$ & & & \\
\hline Tumor site & 0.4560 & 1.1240 & $0.827-1.528$ & & & \\
\hline Tumor size & 0.6090 & 0.8710 & $0.513-1.479$ & & & \\
\hline Tumor differentiation & 0.0620 & 1.3970 & $0.983-1.985$ & & & \\
\hline T-stage & 0.0020 & 2.0130 & $1.305-3.104$ & 0.093 & 1.465 & $0.938-2.286$ \\
\hline N-stage & $<0.001$ & 2.5990 & $1.525-4.428$ & 0.002 & 2.430 & $1.402-4.213$ \\
\hline M-stage & $<0.001$ & 7.5280 & $3.860-14.683$ & $<0.001$ & 6.657 & $3.258-13.604$ \\
\hline BPIFA1 & 0.0010 & 2.7930 & $1.515-5.146$ & 0.049 & 1.903 & $1.002-3.615$ \\
\hline
\end{tabular}

HR, hazard ratio; CI, confidence interval; T, tumor; N, node; M, metastasis; BPIFA1, BPI fold-containing family A member 1.

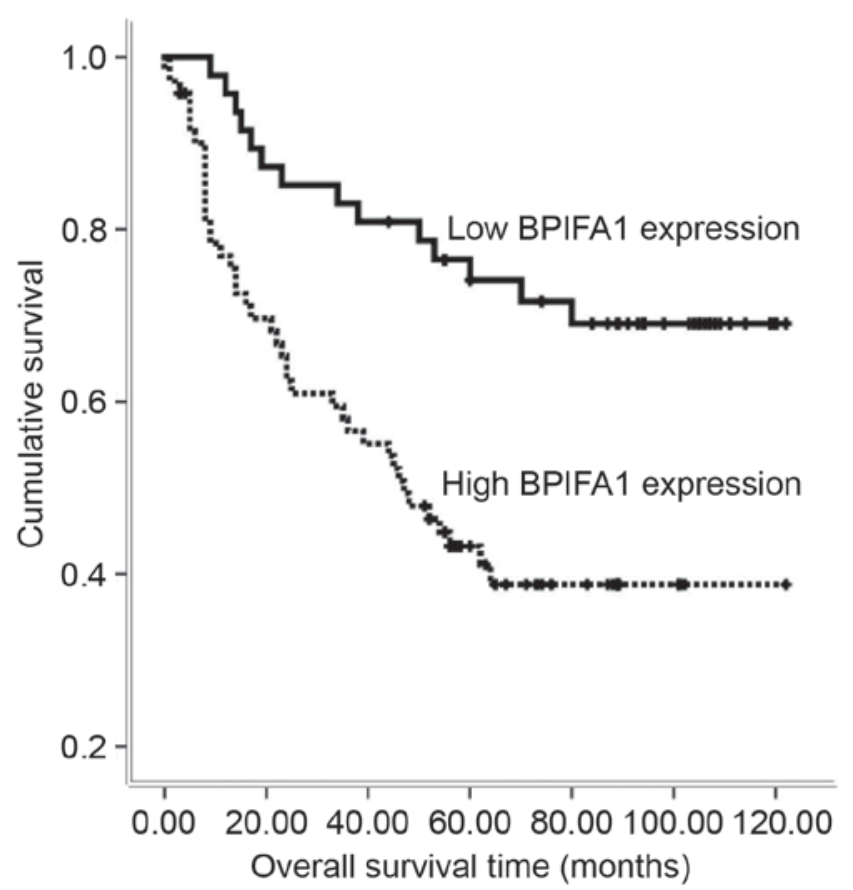

Figure 3. Kaplan-Meier survival analysis for overall survival time in 118 patients with CRC according to the BPIFA1 protein expression levels. BPIFA1, BPI fold-containing family A member 1; CRC, colorectal cancer.

patients with CRC, univariate and multivariate analyses were preformed to determine the prognostic value of clinicopathological factors, including sex, age, tumor size, differentiation grade, $\mathrm{T}$-stage, $\mathrm{N}$-stage and distant metastasis. The results revealed that high expression levels of BPIFA1 protein are an independent prognostic factor of disease outcome in patients with CRC (Table II; P=0.049).

\section{Discussion}

The palate, lung and nasal epithelium clone (PLUNC) protein was first described in the epithelium, trachea and bronchus of mouse embryos (24); subsequently, a family with ten members of human equivalents was recorded (9). Based on their predicted structure of being homologous to one or both domains of the bactericidal or permeability-increasing protein (BPI), PLUNCs can be subdivided in two groups: Short (SPLUNC) and long (LPLUNC) proteins (11). Recently, PLUNC family members have been included in the BPI fold-containing superfamily, leading to a novel nomenclature whereby SPLUNC1 protein has the designation BPIFA1 $(25,26)$.

Previously, various antimicrobial activities have been attributed to BPIFA1, in addition to evidence that it may function as a host defense protein $(4,6,7)$. However, the specific function of BPIFA1 has not yet been well defined. In prior studies, its expression was detected in lung cancer (12-14,20), gastric cancer (15), salivary gland tumors (16-19) and nasopharyngeal carcinoma (19). However, to the best of our knowledge, there have been no reports investigating the role of BPIFA1 in CRC.

Therefore, the current study presents the first evidence that BPIFA1 expression is upregulated at the transcriptional and translational levels in CRC tissues, compared with in normal mucosa tissues. These finding suggest that the upregulation of BPIFA1 in CRC may be associated with the carcinogenesis of CRC. BPIFA1 was overexpressed in CRC and weakly expressed in normal colon mucosa tissue, which suggested that BPIFA1 may be a potentially superior diagnostic marker for CRC.

Notably, the upregulation of BPIFA1 was significantly associated with tumor invasion depth (T-stage), positive regional lymph node metastasis (N-stage) and distant metastasis (M-stage) of patients with CRC. Local invasion is the initial step in tumor metastasis. Metastatic colonization at a distant tissue is a key step in the metastatic cascade (27). The overexpression of BPIFA1 was significantly associated with invasion and migration of CRC cells, suggesting that BPIFA1 may serve a critical role in the metastatic cascade of CRC. The results of the present study are consistent with those of certain previous studies; Iwao et al (14) identified BPIFA1 to be a marker of micrometastasis in NSCLC and Zheng et al (20) observed that BPIFA1 promotes lung cancer cell migration and proliferation by targeting $14-3-3 \zeta$ and $14-3-3 \theta$ proteins. The metastasis of tumor cells to vital organs is responsible for the majority of cancer-associated mortalities. The present results 
indicated that targeting BPIFA1 may exert an anti-metastasis effect and prolong the survival time of patients with CRC.

The present study also demonstrated an association between BPIFA1 expression and the prognosis of patients with CRC. The results indicated that BPIFA1 protein expression level is inversely associated with overall survival. Patients with CRC and a high level of BPIFA1 expression experienced a shorter survival time. In univariate and multivariate analyses, a high expression level of BPIFA1 protein was associated with an increased risk of mortality from $\mathrm{CRC}$, indicating that a high expression level of BPIFA1 may be an independent factor for poor prognosis for patients with CRC. These findings are consistent with those of a previous study investigating gastric cancer (15) and lung cancer (20), wherein the upregulation of BPIFA1 was revealed to be associated with advanced disease stage and/or poor prognosis. Therefore, these results suggested that overexpression of BPIFA1 may be a promising predictor of prognosis and a potential therapeutic target for CRC.

In conclusion, the results of the present study have extended previous findings regarding the role of BPIFA1 in cancer progression. The present study revealed that BPIFA1 expression was upregulated in CRC tissues and, for the first time, highlighted the clinical and prognostic significance of BPIFA1 in CRC. The elevated BPIFA1 expression level was associated with tumor invasion and metastasis, which is significantly associated with tumor progression in patients, leading to a poor clinical outcome. These results indicated that BPIFA1 may have potential as a clinical predictor for aggressive phenotypes and as a prognostic predictor for patients with CRC. However, further studies are required in order to verify the molecular mechanisms underlying the function of BPIFA1, and to illustrate the therapeutic value of BPIFA1 for the treatment of CRC.

\section{Acknowledgements}

The present study was supported by the National Natural Science Foundation of China (grant nos. 81172242 and 8147238).

\section{References}

1. Bernard W: Stewart CPW: World cancer report 2014: IARC, 2014

2. Lukinskiene L, Liu Y, Reynolds SD, Steele C, Stripp BR, Leikauf GD, Kolls JK and Di YP: Antimicrobial activity of PLUNC protects against Pseudomonas aeruginosa infection. J Immunol 187: 382-390, 2011.

3. Gally F, Di YP, Smith SK, Minor MN, Liu Y, Bratton DL, Frasch SC, Michels NM, Case SR and Chu HW: SPLUNC1 promotes lung innate defense against Mycoplasma pneumoniae infection in mice. Am J Pathol 178: 2159-2167, 2011.

4. Ghafouri B, Kihlström E, Ståhlbom B, Tagesson C and Lindahl M: PLUNC (palate, lung and nasal epithelial clone) proteins in human nasal lavage fluid. Biochem Soc Trans 31: 810-814, 2003

5. Sayeed S, Nistico L, St Croix C and Di YP: Multifunctional role of human SPLUNC1 in Pseudomonas aeruginosa infection. Infect Immun 81: 285-291, 2013.

6. Bingle L, Barnes FA, Cross SS, Rassl D, Wallace WA, Campos MA and Bingle CD: Differential epithelial expression of the putative innate immune molecule SPLUNC1 in cystic fibrosis. Respir Res 8: 79, 2007.

7. Di YP, Harper R, Zhao Y, Pahlavan N, Finkbeiner W and Wu R: Molecular cloning and characterization of spurt, a human novel gene that is retinoic acid-inducible and encodes a secretory protein specific in upper respiratory tracts. J Biol Chem 278: $1165-1173,2003$.
8. Chu HW, Thaikoottathil J, Rino JG, Zhang G, Wu Q, Moss T, Refaeli Y, Bowler R, Wenzel SE, Chen Z, et al: Function and regulation of SPLUNC1 protein in Mycoplasma infection and allergic inflammation. J Immunol 179: 3995-4002, 2007.

9. Bingle CD and Bingle L: Characterisation of the human plunc gene, a gene product with an upper airways and nasopharyngeal restricted expression pattern. Biochim Biophys Acta 1493: 363-367, 2000.

10. Bingle CD and Gorr SU: Host defense in oral and airway epithelia: Chromosome 20 contributes a new protein family. Int J Biochem Cell Biol 36: 2144-2152, 2004.

11. Bingle CD and Craven CJ: PLUNC: A novel family of candidate host defence proteins expressed in the upper airways and nasopharynx. Hum Mol Genet 11: 937-943, 2002.

12. Bingle L, Cross SS, High AS, Wallace WA, Devine DA, Havard S, Campos MA and Bingle CD: SPLUNC1 (PLUNC) is expressed in glandular tissues of the respiratory tract and in lung tumours with a glandular phenotype. J Pathol 205: 491-497, 2005.

13. Cheng M, Chen Y, Yu X, Tian Z and Wei H: Diagnostic utility of LunX mRNA in peripheral blood and pleural fluid in patients with primary non-small cell lung cancer. BMC Cancer 8: 156, 2008.

14. Iwao K, Watanabe T, Fujiwara Y, Takami K, Kodama K, Higashiyama M, Yokouchi H, Ozaki K, Monden M and Tanigami A: Isolation of a novel human lung-specific gene, LUNX, a potential molecular marker for detection of micrometastasis in non-small-cell lung cancer. Int J Cancer 91: 433-437, 2001.

15. Sentani K, Oue N, Sakamoto N, Arihiro K, Aoyagi K, Sasaki H and Yasui W: Gene expression profiling with microarray and SAGE identifies PLUNC as a marker for hepatoid adenocarcinoma of the stomach. Mod Pathol 21: 464-475, 2008.

16. Vargas PA, Speight PM, Bingle CD, Barrett AW and Bingle L: Expression of PLUNC family members in benign and malignant salivary gland tumours. Oral Dis 14: 613-619, 2008.

17. Gonzalez-Arriagada WA, Santos-Silva AR, Ito FA, Vargas PA, Speight PM, Bingle L and Lopes MA: Expression pattern of PLUNC proteins as an auxiliary tool for the diagnosis of high-grade mucoepidermoid carcinoma of the salivary gland. J Oral Pathol Med 41: 589-597, 2012.

18. He Y, Zhou G, Zhai Y, Dong X, Lv L, He F and Yao K: Association of PLUNC gene polymorphisms with susceptibility to nasopharyngeal carcinoma in a Chinese population. J Med Genet 42: 172-176, 2005.

19. Zhang B, Nie X, Xiao B, Xiang J, Shen S, Gong J, Zhou M, Zhu S, Zhou J, Qian J, et al: Identification of tissue-specific genes in nasopharyngeal epithelial tissue and differentially expressed genes in nasopharyngeal carcinoma by suppression subtractive hybridization and cDNA microarray. Genes Chromosomes Cancer 38: 80-90, 2003.

20. Zheng X, Cheng M, Fu B, Fan X, Wang Q, Yu X, Sun R, Tian Z and Wei H: Targeting LUNX inhibits non-small cell lung cancer growth and metastasis. Cancer Res 75: 1080-1090, 2015.

21. Pietruszewska W, Bojanowska-Poźniak K and Kobos J: Matrix metalloproteinases MMP1, MMP2, MMP9 and their tissue inhibitors TIMP1, TIMP2, TIMP3 in head and neck cancer: An immunohistochemical study. Otolaryngol Pol 70: 32-43, 2016.

22. Wang S, Zhou J, Wang XY, Hao JM, Chen JZ, Zhang XM, Jin H, Liu L, Zhang YF, Liu J, et al: Down-regulated expression of SATB2 is associated with metastasis and poor prognosis in colorectal cancer. J Pathol 219: 114-122, 2009.

23. Wang S, Yang MH, Wang XY, Lin J and Ding YQ: Increased expression of miRNA-182 in colorectal carcinoma: An independent and tissue-specific prognostic factor. Int J Clin Exp Pathol 7: 3498-3503, 2014.

24. Weston WM, LeClair EE, Trzyna W, McHugh KM, Nugent P, Lafferty CM, Ma L, Tuan RS and Greene RM: Differential display identification of plunc, a novel gene expressed in embryonic palate, nasal epithelium, and adult lung. J Biol Chem 274: 13698-13703, 1999.

25. Bingle L and Bingle CD: Distribution of human PLUNC/BIP fold-containing (BPIF) proteins. Biochem Soc Trans 39: 1023-1027, 2011.

26. Bingle CD, Seal RL and Craven CJ: Systematic nomenclature for the PLUNC/PSP/BSP30/SMGB proteins as a subfamily of the BPI fold-containing superfamily. Biochem Soc Trans 39: 977-983, 2011.

27. Valastyan S and Weinberg RA: Tumor metastasis: Molecular insights and evolving paradigms. Cell 147: 275-292, 2011. 